Como citar: Silva, A. C. P., Santiago, M. C. M., Aguiar, J., Rubert, L. M., Cassel, P. A., Bittencourt, M. F., \& Abaid, J. L. W. (2020). Orientação Parental em Grupo com Cuidadores de Adolescentes: um Relato de Experiência. PSI UNISC, 4(2), 165-185. doi: 10.17058/psiunisc.v4i2.14944

\title{
Orientação Parental em Grupo com Cuidadores de Adolescentes: um Relato de Experiência
}

Orientación Parental Grupal con Cuidadores Adolescents: un Informe de Experiencia Group Parental Guidance with Adolescent Caregivers: an Experience Report

\section{Ana Claudia Pinto da Silva}

Universidade Franciscana (UFN), Santa Maria - RS/Brasil ORCID: 0000-0002-2777-6023

E-mail: anaclaudiaps14@hotmail.com

Monique Corrêa de Melo Santiago

Pedagoga e Educadora Parental, Santa Maria - RS/Brasil ORCID: 0000-0002-2092-9074

E-mail: moniquemelo@gmail.com

Jessica Aguiar

Universidade Franciscana (UFN), Santa Maria - RS/Brasil ORCID: 0000-0002-6390-7684

E-mail: aguiarjessica1@gmail.com

Luiza Müller Rubert

Universidade Franciscana (UFN), Santa Maria - RS/Brasil ORCID: 0000-0002-5907-7497

E-mail: luiza.rm532@gmail.com

Paula Argemi Cassel

Consultório Particular de Psicologia, Santa Maria - RS/Brasil ORCID: 0000-0003-2556-4067

E-mail: paula.acassel@gmail.com

Marcli Firpo Bittencourt

Universidade Franciscana (UFN), Santa Maria - RS/Brasil ORCID: 0000-0002-3931-2824

E-mail: marclib@bol.com.br

Josiane Lieberknecht Wathier Abaid Universidade Franciscana (UFN), Santa Maria - RS/Brasil ORCID: 0000-0002-5746-5349

E-mail: josianelieb@yahoo.com.br

\section{Resumo}

Realizou-se um estudo qualitativo, com objetivo de descrever as sessões de intervenção de um grupo de orientação de pais para cuidadores de adolescentes. A intervenção se deu em dez sessões, de uma hora semanal, previamente estruturadas. Participaram cinco cuidadoras. Os instrumentos utilizados foram diários de campo produzidos pelas pesquisadoras que realizaram as intervenções no grupo e entrevistas semiestruturadas com as participantes, aplicada um encontro antes da primeira sessão da intervenção. Os resultados foram analisados quanto ao seu conteúdo, de onde se originaram três categorias: comunicação efetiva, parentalidade e uso de telas exemplificados em cada uma das dez sessões. Percebe-se a importância da intervenção em grupo para orientação parental através das mudanças cotidianas na organização familiar, incremento na comunicação das cuidadoras com seus filhos, seguimento de rotina por parte do adolescente, sob orientação parental e promoção de escuta ativa, clara e aberta das cuidadoras com os adolescentes. 
Palavras-chaves: Adolescente; Educação em saúde; Parentalidade.

\section{Resumen}

Se realizó un estudio cualitativo, con el objetivo de describir las sesiones de intervención de un grupo de orientación de padres para cuidadores adolescentes. La intervención tuvo lugar en diez sesiones, una hora a la semana, previamente estructuradas. Participaron cinco cuidadores. Los instrumentos utilizados fueron diarios de campo producidos por los investigadores que llevaron a cabo las intervenciones en el grupo y entrevistas semiestructuradas con los participantes, con una reunión aplicada antes de la primera sesión de la intervención. Los resultados se analizaron en cuanto a su contenido, de donde se originaron tres categorías: comunicación efectiva, crianza y uso de pantallas ejemplificadas en cada una de las diez sesiones. Se percibe la importancia de la intervención grupal para la orientación de los padres a través de los cambios diarios en la organización familiar, el aumento de la comunicación de los cuidadores con sus hijos, el seguimiento rutinario del adolescente, bajo la orientación de los padres y la promoción de una escucha activa, clara y abierta de los niños. cuidadores con adolescentes.

Palabras clave: Adolescente; Educación para la salud; Paternidad.

\begin{abstract}
A qualitative study was carried out, with the objective of describing the intervention sessions of a parent orientation group for adolescent caregivers. The intervention took place in ten sessions, one hour a week, previously structured. Five caregivers participated. The instruments used were field diaries produced by the researchers who carried out the interventions in the group and semi-structured interviews with the participants, with a meeting applied before the first session of the intervention. The results were analyzed as to their content, from which three categories originated: effective communication, parenting and use of exemplified screens in each of the ten sessions. It is perceived the importance of group intervention for parental guidance through daily changes in family organization, increase in the communication of caregivers with their children, routine follow-up by the adolescent, under parental guidance and promotion of active, clear and open listening to children. caregivers with teenagers.
\end{abstract}

Keywords: Adolescent; Health education; Parenting.

\section{Introdução}

A adolescência é um período em que ocorrem mudanças significativas tanto biologicamente, como no desenvolvimento cognitivo e social. Trata-se de um período significativo que pode ser vivenciado e expressado conforme o período históricocultural vigente e se modificam conforme a realidade de cada adolescente (Naves, 2016; Senna \& Dessen, 2015). Sob ponto de vista cronológico, a World Health Organization [WHO] (2017) considera a adolescência o período de transição entre a infância e a vida adulta, entre as idades dos 10 aos 19 anos. Ainda, esta organização refere que este momento do desenvolvimento pode ser dividido em adolescência inicial (10-14 anos) e final (15-19 anos).

A socialização dos adolescentes se fundamenta nas relações que possuem com os cuidadores, geralmente, os pais. Estes devem possuir responsabilidades em ofertar um ambiente seguro e estável, que valida e legitima as competências e autonomia do indivíduo, com continência, apresentando limites realistas, bem como possibilitar acolhimento das expressões emocionais e de aspirações manifestadas pelos filhos (Bolsoni-Silva \& Loureiro, 2011; Sousa \& Cruz, 2016; Wainer \& Wainer, 2016; World Health Organization [WHO], 2017). A relação entre cuidadores e filhos, portanto, envolvem aceitação e expressão de pertencimento, cuidado, afeto, proteção, com mediação entre exigência (limite), responsividade (comunicação) e warming (afetividade) (Fava, Rosa, \& Olivia, 2018).

Consonante, a teoria de apego é uma das perspectivas desenvolvimentais sobre vinculação entre seres humanos, elaborada para descrever uma teoria de como se dá a vinculação dos seres humanos (Bowlby, 1989b). A teoria do apego compreende que bebês precisam estabelecer um relacionamento com seu cuidador para que possam se desenvolver. Esse desejo de proximidade expressado pela criança é chamado de apego, e inicialmente exprime as necessidades de segurança e proteção do recém-nascido. Essas 
duas irão constituir os pilares da saúde mental do infante, pois a forma como os pais desenvolvem esse vínculo inicial está diretamente associada aos padrões de apego que a criança irá desenvolver (Ramires \& Schneider, 2010).

O adulto cuidador, por sua vez, também deve expressar uma reação emocional de reciprocidade com o bebê. Apego, então, é um tipo de vínculo no qual o senso de segurança de alguém está estreitamente ligado à figura de apego. No relacionamento com a figura de apego, a segurança e o conforto experimentados na sua presença permitem que seja usado como uma "base segura", a partir da qual poderá se explorar o resto do mundo (Bowlby, 1997c), ou seja, o papel que os cuidadores desempenham e as respostas refletidas nas funções parentais são fundamentais na construção do apego e no desenvolvimento da personalidade do indivíduo (Bowlby, 1989b).

Portanto, o contexto familiar, assim como sua organização, deve ser analisado de forma atenta, já que as consequências do modo pelo qual os membros familiares se relacionam, poderão repercutir em todos, incluindo os filhos. Sabe-se que o comportamento dos filhos pode ser entendido como reflexo do que vivem em seus lares, além das atitudes familiares se conectarem e acompanharem estes indivíduos ao longo da vida (Sales, 2016).

A teoria do apego tem sido base para diferentes abordagens terapêuticas, dentre elas a Terapia dos Esquemas, a qual compreende que o funcionamento dos cuidadores frente à relação parental se dá através dos esquemas que vão modulando o modo de ser e agir frente a educação e relação estabelecida com os filhos, tendo também influência no padrão de ensinamentos no que se refere ao manejo das práticas parentais. A Terapia CognitivoComportamental trabalha com a formação e reformulação de crenças dos indivíduos, sendo que as mesmas consistem em ideias gerais, globais, rígidas e generalizadas para centenas de situações que a pessoa vivencia no dia-a-dia e nas relações familiares (Neufeld, Benedetti,
\& Caminha, 2017). Os esquemas e as crenças dos cuidadores sofreram também interferências da forma pela qual foram cuidados, demarcando a transgeracionalidade afetiva existente nos estilos parentais (Wainer \& Wainer, 2016).

A qualidade da relação estabelecida entre cuidadores e filhos, além da forma pela qual a relação familiar se estabelece, interferem em todos os membros da família e possuem potencial de afetar a saúde mental de toda a família, principalmente crianças e adolescentes. Nesse sentido, as práticas educativas parentais, expressas nas habilidades sociais como cuidadores, possuem repercussões no repertório dos filhos. Portanto, o estilo parental e a ideia dos pais são fatores importantes para o desenvolvimento psicológico e comportamental dos filhos (Bettencourt, 2017), indicando que as ações parentais exercidas pelos cuidadores podem produzir prejuízos ou segurança para os adolescentes (Bolsoni-Silva \& Loureiro, 2011; Sousa \& Cruz, 2016 WHO, 2017).

O desenvolvimento ainda em percurso de funções cognitivas complexas, especificamente, entendidas como funções executivas, do adolescente podem por vezes facilitar em determinados momentos a alteração de humor e afeto, a impulsividade e elevar a influência dos amigos na tomada de decisão, podendo motivar comportamentos de risco. As funções executivas são definidas como conjunto de habilidades mentais que ajudam o indivíduo a realizar tarefas de forma independente e direcionada para metas. Essas funções, quando integradas, capacitam o indivíduo a tomar decisões, avaliar e adequar seus comportamentos e estratégias, buscando a resolução para um problema. Além disso, facilitam o gerenciamento das outras habilidades cognitivas (Miranda, 2018). O período da adolescência costuma ser caracterizado como um momento, no qual os cuidadores têm dificuldade de compreender e acompanhar tantas mudanças ao mesmo tempo (Senna \& Dessen, 2015). 
Ainda em relação às modificações cerebrais que ocorrem na adolescência relacionam-se ao amadurecimento de circuitos cerebrais corticais e subcorticais, entende-se que não somente a maturação, mas também as mudanças ligadas às influências ambientais e socioculturais, possibilitam uma visão mais complexa e heterogênea quando se analisa o padrão de desenvolvimento das diferentes áreas cerebrais durante a essa fase. Dois novos pilares teóricos da neurociência moderna, a plasticidade cerebral e a epigenética, implicam um aprofundamento do conhecimento com relação às mudanças da conectividade cerebral frente aos desafios ambientais referentes a neuroplasticidade (Muszkat, Miranda, \& Muszkat, 2015).

O modo como cada família estabelece as regras, toma as decisões, supervisiona e comunica-se com os filhos, são considerados fatores fundamentais na educação dos jovens e possuem uma influência direta em seus desenvolvimentos (Benetti, Vieira, \& Faracco, 2016). Nessa direção, a invenção e propagação da tecnologia é uma das grandes responsáveis pela mudança na rotina de milhares de pessoas. Adolescentes são, cada vez mais, expostos à telas eletrônicas, com uso excessivo associado a dificuldades parentais no manejo e orientação dos filhos no que diz respeito ao uso de telas eletrônica (Spizzirri, Wagner, Mosmann, \& Armani, 2012). O aumento do acesso às tecnologias tem sido, portanto, responsável por influenciar significativamente as relações dos adolescentes com aqueles que fazem parte de seu contexto, ou seja, colegas, amigos, educadores e até mesmo familiares (Silva \& Silva, 2017).

Diante desse cenário, uma atenção especial por parte dos cuidadores é necessária para que as consequências do uso intenso de telas eletrônicas sejam possíveis de adequado manejo. Possibilidades de resultados do uso de telas podem incluir: isolamento social no qual o indivíduo poderá desencadear psicopatologias, tais como, depressão, ansiedade, sentimentos de solidão e retraimento afetivo. $\mathrm{O}$ uso das tecnologias digitais, como, computadores e celulares com acesso a internet, assim como os jogos digitais, vêm mudando a maneira como os integrantes da família se comunicam, gerando assim um distanciamento social e afetivo (Park, Han, Kim, Cheong, \& Lee, 2016). Por meio, de estudos observa-se uma redução significativa do tempo de convivência entre os membros ou tornando-o menos proveitoso pela interferência atencional dos meios digitais (Bueno \& Lucena, 2016).

Então tornar-se pai, mãe ou cuidador requer de responsabilidades, mas sabe-se que essa função vem carregada de muitas incertezas e desafios frente a parentalização dos filhos, estudos abordam que no geral os cuidadores não estão preparados para executar as ações parentais. Assim, os mesmos acabam buscando por dicas ou sugestões de pessoas da família, no qual utilizam na maioria das vezes técnicas sustentadas em vivências de outros pais, sendo que muitas delas podem vir a não corresponder aos desejos esperados pelos cuidadores, sendo assim experiências de tentativas de erros e acertos (Rodrigues, 2019).

A educação parental é considerada uma ferramenta importante frente ao manejo parental, no que se refere às dificuldades e desafios encontrados no exercício da parentalidade. A mesma busca reafirmar a família como socialmente responsável na educação dos adolescentes, por meio da parentalidade positiva, conduzida através de medidas de proteção e preservação dos vínculos familiares, que são proporcionadas por orientações sobre as práticas educativas parentais. Estes ensinamentos possibilitam à família fazer parte e auxiliar nas situações de risco que são vivenciadas pelos menores (Bettencourt, 2017).

Este tipo de orientação às famílias tem como função prevenir práticas parentais negligentes ou coercitivas, que utilizam de punições físicas ou violência psicológica. Os familiares são instigados a assumir o papel de responsáveis no cuidado das crianças e adolescentes, estimulando um desenvolvimento saudável através do enfoque nos aspectos positivos que fortalecem o grupo familiar (Garcia, Yunes, \& Almeida, 2016). 
Entende-se a relevância da orientação parental por propiciar à diminuição das dificuldades parentais no manejo da relação familiar, consequentemente, a redução de problemas comportamentais e emocionais dos filhos (Rodrigues, 2019).

A comunicação entre os membros da família é essencial, mesmo que seja difícil para muitos pais, pois o adolescente deseja ser compreendido e busca por empatia e respeito frente a singularidade que está constituindo, espera-se apoio e compreensão em relação às demandas advindas da adolescência. Para além destas questões, é necessário também assertividade dos cuidadores, por meio de orientações claras e concisas para o adolescente, bem como instruir o adolescente sobre a sua responsabilidade, promovendo equilíbrio na relação, tornando a educação responsável e comprometida consonante com o desenvolvimento do adolescente (Barreto \& Rabelo, 2015).

Para que os cuidadores possam manter uma comunicação eficiente é importante a utilização de recursos, como, a Comunicação Não Violenta (CNV), que envolve questões voltadas para a linguagem, pensamentos e diálogo visando fazer com que o indivíduo desenvolva uma maior qualidade em sua comunicação proporcionando mais conforto e bem estar comum (Rosenberg, 2019a). Associado a Disciplina Positiva (DP) possui papel fundamental na orientação de adultos, a fim de estarem abertos para escutar e entender os desejos dos filhos, podendo haver acordos através do diálogo (Fava et al., 2018).

Partindo dessa perspectiva, é interessante apontar a eficácia dos grupos de educação parental na modificação de estratégias de parentalidade em cuidadores de crianças e adolescentes, utilizando-se técnicas da Terapia Cognitivo Comportamental (TCC) e da Terapia de Esquemas (TE) (Guisso, Bolze, \& Vieira, 2019; Neufeld, Godoi, Rebessi, Maehara, \& Mendes, 2018; Pazzetto \& Toni, 2018). Estudos afirmam que apesar da limitada produção de trabalhos científicos sobre orientação parental, os realizados nacionalmente e internacionalmente baseados na TCC demonstraram que a educação parental tem efeito positivo significativo no manejo frente aos desafios da parentalidade (Lima \& Cardoso, 2018; Neufeld et al., 2017).

Os grupos de educação parental em TCC demonstram efetividade mediante o uso de técnicas que abarcam o aprofundamento do modelo cognitivo e a reestruturação cognitiva, com a utilização de tarefas de casa como auxílio na psicoeducação dos integrantes do grupo (Neufeld, Maltoni, Ivatiuk, \& Rangé, 2017). Ademais, os grupos com referencial da Terapia de Esquemas proporcionam aos cuidadores o contato e a compreensão dos seus esquemas e estilos parentais, assumindo a responsabilidade pela sua postura parental e oportunizando um ambiente mais validante para os filhos (Wainer \& Wainer, 2011).

Diante do que foi abordado, e da necessidade de promover, por meio de grupos de orientação parental, a implementação de medidas preventivas que viabilizem os aspectos positivos e afetivos da comunicação entre pais e filhos, este artigo teve como objetivo descrever as sessões de intervenção de um grupo de orientação de pais para cuidadores de adolescentes.

\section{Método \\ Delineamento do estudo}

O estudo é caracterizado como uma pesquisa qualitativa, onde serão apresentados dados por meio de relatos via diário de campo. A análise dos dados foi realizada a partir da análise de conteúdo (Bardin, 2016) mediante estipulação de categorias criadas de forma geral, a partir das impressões e sentimentos das mediadoras, bem como por meio da enunciação e das verbalizações que foram marcantes para as participantes. O diário de campo foi lido por juízes independentes e, para apresentação dos resultados, foram elencadas categorias para análise a partir de todas as sessões relatadas. A pesquisa com enfoque qualitativo tem como finalidade o entendimento aprofundado de um evento na sua dimensão individual ou social, através dos aspectos subjetivos que envolvem 
cada realidade, sendo assim os acontecimentos não devem ser quantificados (Neves, 2015).

\section{Participantes}

Participaram deste estudo cinco cuidadoras de adolescentes, sendo duas avós, uma materna e a outra paterna, uma madrasta e duas mães, com idades entre 30 a 70 anos. $\mathrm{O}$ número de cuidadores foi superior ao número de adolescentes devido a participação de duas cuidadoras que exerciam o cuidado ao mesmo adolescente. A faixa etária dos adolescentes por quem eram responsáveis era de 13 a 15 anos, sendo total de quatro adolescentes, dois deles eram do sexo masculino e duas do sexo feminino. No que diz respeito aos dados socioeconômicos destas participantes, pode-se observar quanto à escolaridade, que três delas possuíam ensino médio completo e as outras duas ensino superior, uma completo e outra incompleto, mas estava cursando. Em relação à renda familiar, variou de um a dois salários mínimos, sendo que de duas a cinco pessoas dependem desse valor mensal. E sobre o estado civil das cuidadoras todas estavam casadas ou vivendo com companheiro no momento da pesquisa.

$\begin{array}{ccccr}\text { Os critérios } & \text { de } & \text { inclusão } & \text { das } \\ \text { participantes } & \text { foram } & \text { ser } & \text { cuidadoras } & \text { de }\end{array}$ adolescentes, os quais iniciaram atendimento clínico, em um grupo terapêutico no Laboratório de Práticas em Psicologia de uma universidade privada do interior do Rio Grande do Sul. Os jovens foram indicados para atendimento psicológico devido a presença de sintomatologia de comportamentamentos internalizantes, tais como, tristeza, sintomas deprimidos e baixa-autoestima e externalizantes, tal como, comportamentos de agressão, além de questões comuns da adolescência. Dessa forma, a amostra foi constituída por conveniência.

\section{Instrumentos}

Entrevistas semiestruturadas foram realizadas com as cuidadoras, de forma individual, antes de iniciar a intervenção. Os depoimentos foram compilados no diário de campo pelas pesquisadoras, uma vez que as participantes não aceitaram gravar entrevistas. Desse modo, a entrevista inicial com as famílias tinha como finalidade principal conhecer as realidades, demandas e rotinas diárias dos adolescentes e cuidadoras. Esse instrumento foi construído pelas pesquisadoras, no qual pretendiam fazer mapeamento da compreensão das cuidadoras sobre os processos de desenvolvimento dos adolescentes, bem como fazer uma retomada das suas próprias vivências a respeito deste período, buscando um processo empático para com aqueles que eram cuidados. Esse foi um momento para que elas também pudessem se deparar com as mudanças culturais da sociedade contemporânea e as influências sociais na educação dos adolescentes.

Além disso, foi aplicado um questionário socioeconômico, que teve como finalidade verificar o perfil sociodemográfico das famílias envolvidas na pesquisa, tais como: o nível de escolaridade, qualidade de vida, estado civil, idade das participantes, eventos relevantes envolvendo a conjuntura familiar e as práticas educativas dos cuidadores.

Um diário de campo foi produzido semanalmente pelas mediadoras do grupo, no qual era descrito o tema abordado em cada encontro, se o propósito do encontro havia sido alcançado ou não e o porquê, os principais desafios frente à mediação do grupo de educação parental, e ainda, os relatos, percepções, sentimentos e comentários tanto das participantes quanto das mediadoras. Das três mediadoras que atuaram diretamente com o grupo parental, duas são co-autoras deste artigo e as demais pesquisadoras compõem a equipe técnica do projeto de extensão e possuem acesso ao material da pesquisa de campo. Esse instrumento representou uma forma de registrar as observações, reflexões e comentários das participantes da pesquisa e das mediadoras do grupo, para o uso individual ou coletivo dos pesquisadores. Desse modo, o mesmo propiciou às pesquisadoras a criação de uma rotina em observar com atenção e relatar com exatidão os acontecimentos diários de forma sistemática e detalhada de todo os 
processos da pesquisa (Freitas \& Pereira, 2018).

\section{Procedimentos e considerações éticas}

No primeiro momento foi realizado o convite às cuidadoras para participarem do projeto de educação parental, onde foram informadas dos riscos e benefícios por meio do Termo de Consentimento Livre Esclarecido (TCLE). Após o convite foram realizadas entrevistas semiestruturadas com as cuidadoras de forma individual, com o intuito de promover um espaço inicial de acolhimento às demandas e um momento de familiarização das vivências de cada composição familiar e aplicação do questionário socioeconômico para verificar o perfil das famílias. Já os diários de campo eram produzidos semanalmente pelas mediadoras do grupo de educação parental, onde era descrito as falas das participantes e observações feitas pelas mediadoras.

O protocolo utilizado para as oito sessões de intervenção foi adaptado de Wainer e Wainer (2011) para pais de filhos com transtornos do comportamento. Para este estudo as sessões de intervenção e as temáticas destas foram planejadas previamente em sessões estruturadas para orientação parental, a partir da entrevista semiestruturada inicial com as participantes, realizada no encontro de pré fase. As sessões de intervenção serão descritas no decorrer dos resultados e discussões.

Ainda no primeiro momento, pré fase, foi realizado o convite às cuidadoras para participarem do projeto de educação parental, onde foram informadas dos riscos e benefícios por meio do Termo de Consentimento Livre Esclarecido (TCLE). Após, o convite e aceite das participantes foram realizadas entrevistas semiestruturadas com as cuidadoras de forma individual, com o intuito de promover um espaço inicial de acolhimento às demandas e um momento de familiarização das vivências de cada composição familiar e aplicação do questionário socioeconômico para verificar o perfil das famílias. Já o diário de campo era produzido semanalmente pelas mediadoras do grupo de educação parental, onde era descrito as falas das participantes e observações feitas pelas mediadoras.

As sessões ocorreram uma vez por semana, com duração de uma hora, sendo oito de intervenção, uma de pré-fase, como descrito acima, e outra de pós-fase da intervenção, totalizando dez encontros com as participantes. As sessões foram estruturadas com técnicas embasadas na Orientação de Pais, Disciplina Positiva, Terapia Cognitiva-Comportamental, Teoria dos Esquemas, Teoria do Apego, Neuropsicologia do Neurodesenvolvimento e Comunicação Não Violenta. Este grupo de orientação parental fez parte do projeto de extensão intitulado "Treinamento de pais como apoio ao trabalho do psicólogo em diferentes contextos". O projeto foi aprovado pelo comitê de ética em pesquisa com seres humanos sob registro do CAAE: 08975619.6.0000.5306, n. 3.224.190.

\section{Resultados e discussões}

Para este estudo utilizou-se um cronograma pré-estabelecido, no qual será apresentado o perfil das participantes, assim como as sessões trabalhadas. Os encontros enfocaram principalmente questões alusivas a comunicação e conexão entre as cuidadoras e os jovens, os desafios que se referem a parentalidade e ao uso exagerado dos adolescentes, no que diz respeito aos aparelhos eletrônicos, segundo as percepções das cuidadoras. Desse modo, aplicou-se a análise de conteúdo qualitativa de Bardin (2016), que ocorreu por meio de três passos essenciais. O primeiro se refere a organização do material (pré-análise), o segundo exploração do material (codificação) e, por fim, o tratamento dos resultados obtidos (categorização). Dá análise de conteúdo extrairam-se três categorias, revisadas por duas juízas, cujo indice de concordância superou 80\%: 1) comunicação efetiva, quando ela é percebida ou mencionada como tendo ocorrido da melhor maneira possível; 2) parentalidade, quando os relatos se referem ao papel ou função de cuidado; 3 ) uso de telas, quando o trecho menciona o conteúdo de uso de tecnologias da comunicação e seus efeitos. A seguir descreve-se brevemente as dez 
sessões de intervenção parental, onde se inserem, quando pertinentes, as categorias encontradas.

\section{Encontro 1 (Pré-fase de intervenção): entrevista, contrato e o "quebra gelo"}

Foi efetuada a apresentação das mediadoras e das participantes do grupo denominado "Pais Mais". Realizou-se no primeiro momento uma entrevista semiestruturada para levantar as demandas e as necessidades das cuidadoras e aplicação do questionário socioeconômico. Bem como, fizeram uma dinâmica de grupo, com objetivo de "quebrar o gelo" e criar reflexão sobre a importância do diálogo e da escuta nas relações. As integrantes concordaram em participar da pesquisa por meio do Termo de Consentimento Livre Esclarecido (TCLE).

Durante o encontro foi unânime o relato sobre a dificuldade de comunicação entre as cuidadoras e os adolescentes, e o isolamento social desses, definido como introspecção, por algumas. A sensação que me causa (uma das mediadoras) é que o isolamento acontece por que as cuidadoras não ofertam possibilidade de convívio e se tem são marcados por críticas e falta de cuidado e afeto. (Tal trecho é pertencente à categoria comunicação efetiva, do diário de campo).

Fazendo menção à demanda principal das cuidadoras, Silva (2015) apresentou em seus estudos que muitos pais possuem dificuldades em estabelecer uma comunicação efetiva, no qual não conseguem acessar ou fazer conexões com os filhos. Nesse período, os adolescentes buscam se relacionar com seus pares, e muitos deles apresentam retraimento e introspecção social. Uma boa relação familiar necessita de uma comunicação eficaz e afetiva entre os membros da família, para que os mesmos consigam passar por essa etapa de forma saudável (Rosenberg, 2019b).

\section{Sessões}

\section{Sessão 1: Contexto familiar}

Como ponto central trabalhou-se "O papel do cuidador no contexto familiar". A partir dessa temática se trouxe questionamentos às participantes, tais como: "Por que estou aqui hoje? O que é família? Qual o papel da família? O que é cuidar de um adolescente? É sabido o que ele faz em seu tempo livre? O que ele assiste nas redes sociais e televisão? Quanto tempo fica em contato com tela? "Como eu entendo o meu papel de mãe/pai ou cuidador?".

Para o grupo de intervenção houve a presença de somente participantes mulheres. Pazzetto e Toni (2018) abordam que as cuidadoras possuem um papel mais ativo frente a educação parental dos filhos. As pesquisas mostram evidências sobre as mudanças perante aos papéis desempenhados pela figura feminina e masculina no que se refere a parentalização dos filhos, mas ainda em muitos lares os cuidados e as responsabilidades dos menores são delegados a função materna, enquanto a cuidador masculino continua sendo visto como provedor da casa. Assim, percebe-se uma sobrecarga no que se refere às exigências e funções da mulher na contemporaneidade.

No momento em que as mediadoras iniciaram a conversa observou-se dúvidas sobre o papel das cuidadoras conforme descrito no diário de campo, na categoria parentalidade.

\section{Quando perguntado "Qual o papel da familia?" notou-se um conflito no entendimento sobre o exercício uma parentalidade respeitosa e consciente, e o fato de ser amigo dos filhos. As cuidadoras saiam do seu papel tradicional para serem amigas dos filhos, deixando uma lacuna no lugar da figura parental autoritativa.}

A fim de compreender como essas indagações possam estar relacionadas à categoria uso de telas elucida-se um trecho, via diário de campo:

As cuidadoras mostraram-se receptivas e mencionaram a dificuldade de se relacionar diante do 
conflito de gerações, em especial pelo uso da tecnologia em excesso. Disseram que os adolescentes não possuíam uma rotina estruturada. Uma das cuidadoras afirmou que faz uso do castigo, para que a filha perceba as consequências de suas ações, e retira o celular como recurso.

A mídia social e a comunicação online representam um papel importante na socialização e no desenvolvimento da personalidade do adolescente. Fonte (2017) explicita que, por meio da internet, o adolescente consegue fazer contatos pessoais que, fora desse meio, não consegue. Entretanto, esses contatos são "superficiais" e de "falsa intimidade" e muitas vezes facilitam o afastamento dos jovens com os cuidadores, assim o adolescente passa a se relacionar com pessoas fora da rede familiar, ficando a mesma deficitária. A maioria das famílias acabam por se depararem com os conflitos e os desafios advindos dos aspectos que envolvem as mudanças nas gerações entre cuidadores e filhos (Botton, Cúnico, Barcinski, \& Strey, 2015).

\section{Sessão 2: Rotina e aspectos importantes da inscrição do apego}

A rotina e a Teoria do Apego foram temas desse encontro, que se iniciou perguntando as cuidadoras como funcionava a rotina da família frente aos cuidados dos filhos e como estabelecer uma rotina adequada para cada família. Foi apresentado um vídeo do experimento do Harlow disponível no site (https://www.youtube.com/watch?v=qiiioOm

Wnqg, 2012) a fim de que houvesse uma aproximação visual e embasada em experimento científico acerca do funcionamento do apego.

Isolamento, falta de amigos e permanências domiciliares dos adolescentes foram relatadas pelas cuidadoras. Em relação a essa observação das mesmas foi explicado sobre a importância de dialogar com os adolescentes em relação a esses incômodos, falar e expressar sobre os seus sentimentos e propor momentos de lazer que conectem os familiares. (Este trecho é pertencente à categoria comunicação efetiva, do diário de campo).

Foi realizada a relação com os conteúdos que foram abordados durante o encontro sobre os limites e regras. Esses princípios são aspectos essenciais na vida cotidiana, que podem ser observados desde a sociedade até o ambiente familiar e passam segurança para os indivíduos sobre o que deve ser feito em determinada situação. Desde a infância é importante que os cuidadores coloquem restrições, no sentido de orientar, na rotina da criança, de forma consistente, mas com o cuidado de possibilitar o diálogo. As regras podem ser negociáveis ou não, bem como a inscrição das consequências frente ao não cumprimento, dessa forma a mesma deve ser apresentada com antecedência, antes da determinação da consequência. A criança compreende o que é esperado dela e aprende a respeitar aos limites impostos, todavia esse modo de funcionar é repercutido por todas as faixas etárias (Fava et al., 2018).

Nessa mesma sessão foram abordados conceitos sobre a Teoria do Apego, conforme a pesquisa realizada por Ainsworth, Blehar, Waters e Wall (2015) que criou uma situação estranha para avaliar os tipos de apego de bebês em relação a suas mães, percebeu que existia três tipos de apego. O primeiro é o apego seguro que demonstra desejo pelo cuidador e se sente mais seguro quando a mãe está longe por um curto período. O segundo é o apego inseguro ansioso/ambivalente constatado quando o cuidador é instável em seus comportamentos, deixando a criança desestabilizada na sua ausência. O terceiro tipo de apego é o inseguro evitativo, no qual a criança nem percebe a ausência do cuidador e inclusive não distingue ele de um estranho.

Ainda, segundo Bowlby (1988a), apesar do apego ser desenvolvido durante o período infantil, o mesmo passa por repercutir durante todas as fases do desenvolvimento humano. 
importante salientar que a forma como os cuidadores desenvolvem esse vínculo inicial para com seus filhos, estão diretamente relacionados com os modos de se relacionar dos adolescentes tanto com seus pares quantos com seus familiares (Becker, Vieira, \& Crepaldi, 2019).

\section{Sessão 3: Desenvolvimento das funções cognitivas e comportamentais em adolescentes}

O funcionamento cerebral do adolescente foi em relação aos processos maturacionais de desenvolvimento de habilidades emocionais, habilidades sociais, com a intenção de que as cuidadoras passassem a ter conhecimento efetivo do que se espera de um adolescente e como manejar, especialmente, na expressão de orientar limites de forma responsiva.

Os estudos de Siegel (2016) demonstram que nos últimos anos descobertas revelaram mudanças na estrutura e no funcionamento cerebral durante a adolescência. O principal centro de controle do cérebro, o córtex pré-frontal, ainda não está suficientemente maduro na adolescência. A imaturidade do córtex explica o comportamento considerado imaturo, que segundo Muszkat, Miranda e Muszkat (2015) se dirige ao neurodesenvolvimento. Nesse processo as Funções Executivas (FE) estão associadas com a capacidade de controlar e coordenar comportamentos e pensamentos complexos. As FE's são um componente central da capacidade de autocontrole ou autorregulação humana, com implicações amplas e significativas para a vida do indivíduo (Miranda, 2018).

Em segundo momento, apresentou-se o processo de individuação com o intuito de trazer clareza sobre as características e os comportamentos socioemocionais durante a adolescência, objetivando criar consciência de que é um período e que quem os adolescentes são hoje não é quem serão para sempre. Embora possam parecer diferente para alguns cuidadores, segundo Nelsen e Lott (2019) os adolescentes ainda não cresceram. Eles querem explorar como são diferentes de seus familiares, como se sentem, o que pensam sobre as coisas e quais seus próprios valores. Esse processo de separação da família é chamado de individuação.

Uma das participantes, Cuidadora 1, após ouvir sobre o período de individuação, a necessidade de privacidade do adolescente e o quanto o uso excessivo da internet potencializa o distanciamento entre pais e filhos ela compartilhou com o grupo o seguinte diálogo que obteve com seu filho, no intuito de resgatar a convivência com ele, conforme trecho alusivo a categoria comunicação efetiva descrita no diário de campo:

Adolescente 1, eu percebi que você tem passado a maior parte do seu tempo jogando no computador. Eu sinto muito a sua falta. É importante para mim passar alguns momentos com você. Podemos combinar um dia da semana $e$ um horário para ficarmos juntos?" Com essa fala pode-se perceber nesta sessão que a Cuidadora 1 conseguiu estabelecer uma rotina de convivência estipulada pelo próprio adolescente, a partir da notificação parental de tal necessidade. Ela utilizou uma comunicação mais efetiva $e$ a ferramenta de Disciplina Positiva: "Eu percebi...", visto que ela relatou a sua observação e mostrou confiança na habilidade do adolescente de descobrir o que poderia ser feito. Verificou-se o zelo da cuidadora em conduzir o diálogo embasado em seus próprios sentimentos e no que era importante para ela, no que tange a sua relação com seu filho, evitando críticas e julgamentos, conforme foi trabalhado na sessão pré-fase.

\section{Sessão 4: Técnica de manejo parental}

A proposta central desta sessão era apresentar os estilos parentais, entretanto $\mathrm{o}$ protocolo foi adaptado devido ao relato de uma 
das cuidadoras. $\mathrm{O}$ relato refere-se à categoria parentalidade, do diário de campo:

Logo no início da sessão uma das cuidadoras compartilhou um desafio que teve, onde relatou ter encontrado roupa suja e absorvente íntimo sujo dentro do armário. Ela relatou o quanto o seu marido é autoritário com as filhas e omisso quanto aos cuidados domésticos. $O$ quanto a limpeza é importante para ela e como ela se frustra quando as filhas não seguem o cronograma de limpeza que ela elaborou. Percebemos a necessidade dela desse espaço de fala e deixamos ela expor os seus desafios sem interrupção. Ao término de sua fala foi perguntado a ela sobre os seus sentimentos referentes aos fatos que relatou e ela apresentou dificuldade em nomeá-los.

As mediadoras do grupo aproveitaram o que foi trazido para realizar uma prática de Reunião de família com todas as participantes. As cuidadoras foram convidadas a pensarem juntas em como poderiam resolver o acontecido, focando em solução e que ela fosse: respeitosa para o adulto e o adolescente, relacionada e útil. Todas participaram, mas tiveram dificuldades em se ater na solução, inicialmente. Após uma das mediadoras exemplificar o processo, cada participante foi sugerindo suas soluções. Sugeriu-se que essa mesma ferramenta - reunião de família -fosse utilizada para que os cuidadores trabalhassem com seus os filhos o limite de tempo de telas, para conseguirem ter um diálogo mais respeitoso, encontrarem a solução junto com os adolescentes (Tal fragmento diz respeito a categoria comunicação efetiva, apresentada no diário de campo).
Sobre esse assunto, Nelsen (2015) afirma que as Reuniões de família - uma das ferramentas da Disciplina Positiva - pode ser um método bem-sucedido para aumentar a cooperação e a proximidade entre os membros da família. Elas ofertam uma oportunidade de elevar valores e tradições familiares. Essas reuniões devem acontecer uma vez por semana, em horário pré-estabelecido e as decisões devem ser tomadas em consenso. A reunião termina com a família fazendo algo em conjunto e que seja divertido para todos.

Ao término da prática duas participantes pontuaram suas conquistas conforme relato mencionado na categoria comunicação efetiva, do diário de campo:

A Cuidadora 1 pontuou que ofilho tem se posicionado mais frente aos colegas, que suas notas melhorarame que inclusive está mais aberto ao diálogo com ela. A Cuidadora 2 mostra-se feliz pelo fato de a neta estar dialogando cada vez melhor com ela, e contou entusiasmada que elas iriam sair juntas no final de semana.

As mediadoras perceberam e relataram tal trecho sobre a categoria parentalidade, apresentada no diário de campo:

Duas cuidadoras, mãe e avó, compareceram a sessão de hoje, apesar do adolescente encontrar-se impossibilitado e faltado a sua sessão de psicoterapia, percebe-se que elas se sentem confortáveis, motivadas em aprender e desfrutam a companhia do grupo. Observou-se a dificuldade dos cuidadores encontrarem soluções criativas e respeitosas para resolverem conflitos com os jovens. Percebemos também que gostam de aprender ferramentas da Disciplina Positiva para solucionar conflitos. A ferramenta reunião de família foi acolhida com bastante interesse $e$ entusiasmo. Nota-se que as atividades práticas são muito bem aceitas trazem conexão e encorajamento ao grupo. 
Nesse sentido, a partir das ferramentas da Disciplina Positiva, percebe-se que esse conteúdo pragmático auxilia os cuidadores de forma a muni-los de informação e atualizarem os seus métodos para lidar com o uso da tecnologia por parte dos adolescentes. Nelsen e Lott (2019) salientam que a tecnologia não é o dispositivo que é bom ou mau, mas como é usado que faz toda a diferença. Os filhos viverão em um mundo diferente daquele onde os pais cresceram, e que poderão se beneficiar bastante com o uso da tecnologia. As autoras sugerem que seja trabalhado com os adolescentes o estabelecimento de diretrizes para o uso de eletrônicos.

\section{Sessão 5: Estilos parentais}

Foram apresentados os Estilos Parentais e possíveis práticas parentais associadas aos estilos, levando as cuidadoras a refletirem sobre: Como foram parentalizadas e como está parentalizando seu filho (a) ou adolescente de quem cuida - qual o estilo de prática parental? Punições corporais funcionam? Quais os efeitos e danos psicológicos com o uso das punições? Como é a configuração da passividade? E quais alternativas podem ser pensadas sobre estilo parental autoritário e passivo?

A partir das análises desses conteúdos constatou-se, tal qual a categoria parentalidade via diário de campo:

Todas as cuidadoras se declararam com o estilo que foram parentalizados como autoritário e se definiram entre os estilos, permissivo, autoritário ou autoritativo. Quando questionadas sobre a sua percepção do estilo em relação ao uso da tecnologia por parte dos adolescentes houve um consenso: todas se consideraram com o estilo indulgente, "permissivo por escolha".
Os estilos parentais dos cuidadores são definidos por meio de um padrão de conjunto de práticas educativas, tendo como finalidade a função de socializar, educar, orientar e dar limites para os filhos. Assim, o modo como cada cuidador exerce sua parentalidade tende a ser diversificada e influenciada por sua própria educação. Todavia, estilos parentais são pilares essenciais frente a comunicação dos pais e filhos, ligações afetivas e da interação que ocorre entre ambos (Fava et al., 2018).

Os estudos de (Almeida Maia \& Soares, 2019; Maccoby \& Martin, 1983) apresentam quatro tipos de estilos parentais. $\mathrm{O}$ estilo permissivo se divide em negligente e indulgente, sendo assim o estilo negligente se caracteriza por pais permissivos por falha, onde demonstram pouco interesse em oferecer assistência emocional e afetiva aos filhos. Já cuidadores indulgentes são permissivos por escolhas. São aqueles cuidadores que não impõem limites adequados e regras precisas, são pais tolerantes e afetivos. Os pais que possuem um padrão de educação autoritário tendem agir de forma rígida, colocando regras, valores e punições severas com alta exigibilidade. E os cuidadores autoritativos, são aqueles que promovem um ambiente de trocas no qual é viável modelar o comportamento do adolescente através do diálogo e do afeto consistente e acolhedor.

Devido a essa percepção sobre a tecnologia, foi disponibilizado um conteúdo, o Podcast "Crianças \& Tela" (Becker \& Stein, 2020), disponível no link (https://www.b9.com.br/shows/mamilos/mami los-218-criancas-telas/) que trata sobre o uso indiscriminado de telas por crianças e o prejuízo cognitivo na linguagem que este ocasiona, por diminuir as interações sociais futuras. Sendo assim foi realizado um combinado com as cuidadoras que na próxima sessão seria debatida as percepções de cada uma das participantes sobre a relação dos adolescentes com o uso da tecnologia e os impactos que são observados.

Sessão 6: Parentalidade positiva 
Nessa sessão foi verificado o posicionamento do grupo acerca de educar sem punição, castigo e recompensa. Apresentou-se o termo "Parentalidade Positiva" e como se trabalha. Os estilos parentais foram revisados e o estilo autoritativo, foi relacionado ao estilo de cuidadores que aplicam a Parentalidade Positiva.

Em vista do que foi trabalhado no encontro, a parentalidade positiva é definida pela autora Bettencourt (2017) como um "comportamento parental" que visa assegurar as necessidades básicas mediante a proteção de riscos, assim como propicia a criação de um espaço saudável para o desenvolvimento dos filhos através de um ambiente acolhedor e autônomo. Igualmente, preza pela promoção das competências cognitivas, sociais e afetivas dos cuidadores pelo adolescente, priorizando a prevenção de qualquer ação de negligência frente aos cuidados parentais.

Em seguida convidou-se as participantes a exporem as suas opiniões sobre o podcast que foi enviado na sessão anterior. $\mathrm{O}$ trecho apresenta a categoria uso de telas, no relato do diário de campo das mediadoras constatou-se que: "As cuidadoras relataram estar perplexas pelos prejuízos que o uso indiscriminado de tecnologia ocasiona na vida das crianças e adolescentes".

Discutiu-se ao final da sessão a relação entre o vício em tecnologia e o isolamento, e a importância de tentar proporcionar outras atividades que induzam a interação social dos adolescentes, possibilitando que eles consigam ter um papel mais ativo no seu processo de amadurecimento cerebral. Como consta no diário de campo, na categoria uso de tela, recorte de uma das cuidadoras (Cuidadora 1), nesta sessão:

Todas as cuidadoras perceberam-se assumir um papel indulgente quanto ao uso de tela. A Cuidadora 1 foi uma das que mais se identificou ao perfil parental quando permite que o filho fique várias horas do dia em jogos sozinho em seu quarto.
Sobre esta colocação específica da Cuidadora 1, categorizada em uso de telas, reporta-se a Pereira (2015), segundo o qual a geração de crianças e adolescentes que vivenciam esse ambiente digital precisam de mediações sobre os limites necessários nas Redes Sociais. É o caso da exposição dos menores de idade a todo tipo de conteúdo (inadequado ou não), publicidade ou ainda, de conteúdos agressivos. Vale mencionar um assunto que tem sido colocado como uma pauta preocupante atualmente sobre a influência de conteúdos e jogos violentos.

A pesquisa TIC Kids Online Brasil (2018) evidenciou o aumento na realização de atividades multimídia por crianças e adolescentes usuários de Internet com idade entre 9 e 17 anos. Segundo a entidade, $83 \%$ da população investigada reportaram ter assistido a vídeos, programas, filmes ou séries on-line. Pela primeira vez na série histórica do estudo, essas atividades passaram a ser as mais frequentes entre as crianças e os adolescentes usuários de Internet no Brasil, superando pesquisas na internet para trabalhos escolares (74\%) e o envio de mensagens instantâneas $(77 \%)$.

\section{Sessão 7: Ferramentas práticas frente à educação parental}

Ferramentas de Disciplina Positiva (DP) e técnicas de Comunicação Não Violenta (CNV) foram apresentadas nessa sessão. Dentre as ferramentas e técnicas apresentou-se: Perguntar ao invés de mandar, onde em vez de ordenar o adulto convida o adolescente a refletir e escolher; Ensinar a resolver problemas em família, no qual aproveita-se um desafio para pensar em várias soluções em conjunto e chegar a um acordo; Controle o seu comportamento (adulto), levando os cuidadores a refletirem que para que os adolescentes controlem seus comportamentos, o adulto precisa ser exemplo e controlar o seu; Erros, no qual se vê os erros como oportunidades de aprendizagem, para adultos e adolescentes, convidando os cuidadores a praticarem a autocompaixão e amabilidade, em vez de se 
envergonhar ou se culparem por atitudes que se arrependem.

No que se refere a CNV trabalhou-se: Escuta ativa, onde se convidou os cuidadores a ouvir sem julgar, interromper, ou explicar, sustentando o silêncio, com intuito de criar conexão com o adolescente antes de orientá-lo; Validação dos sentimentos do adolescente e exposição dos seus; Elaboração de pedidos: claros, de forma gentil e firme.

A fim de compreender como essas ferramentas práticas podem estar relacionadas frente à educação parental, Rosenberg (2019b) considera que nossas palavras em vez de serem reações repetitivas e automáticas, tornam-se respostas conscientes, firmemente baseadas na consciência do que estamos percebendo, sentindo e decidindo. Somos levados a nos expressar com honestidade e clareza, ao mesmo tempo em que damos ao outro uma atenção respeitosa e empática. $\mathrm{O}$ uso da $\mathrm{DP}$ e da $\mathrm{CNV}$ no manejo parental ajuda a reformular a maneira pela qual cuidadores e adolescentes se expressam e ouvem uns aos outros.

Ao término da sessão uma das cuidadoras relatou um acontecimento de alguns anos atrás, transcrito da categoria uso de telas no diário de campo logo após a ocorrência do encontro:

A Cuidadora 3 relatou um caso que ocorreu quando a filha tinha 11 anos. O pai descobriu que a préadolescente, na época, estava se comunicando e enviou fotos nuas a uma mulher mais velha, que a filha havia conhecido pela internet. Quando ela foi descoberta apanhou do pai, e sua mãe acusou a filha e não a acolheu. Foi perguntado a Cuidadora se ela achava que a filha tinha maturidade para compreender o ocorrido e se ela não pensava que a jovem teria sido aliciada. Ela se demonstrou raivosa e disse que a filha sabia muito bem o que fazia, não demonstrando nenhuma empatia ou cuidado responsivo pela criança. Foi notório para as mediadoras do grupo a transferência da responsabilidade em relação ao acesso: tempo de uso e discernimento em relação ao conteúdo, por parte da Cuidadora 3. Ao final da sessão, se recordou sobre alguns conteúdo abordados nesse mesmo encontro e também em sessões anteriores como a imaturidade cerebral, sobre o processo de individuação e a percepção do perigo e sobre as ferramentas da Disciplina Positiva: conexão e empatia antes da correção, acolhimento e sobre os erros como oportunidades de aprendizados, para adultos $e$ crianças. Ao término dessa fala percebeu-se a Cuidadora bastante emocionada. Embora a ela tenha se portado de uma maneira pouco receptiva e até reativa em relação às possibilidades de manejo parental propostas, ao se despedir ela disse a uma das mediadoras: "Queria te dizer que eu acho que se isso que acontecesse hoje, com tudo que eu aprendi aqui, eu agiria diferente. Não $100 \%$ como você falou, mas um pouco melhor eu ia conseguir fazer".

Salienta-se que a prática de aliciamento realizada com os menores por meio de aplicativos de comunicação via internet é crime e possuem penalidades impostas a quem vir a praticar, isso está descrito no Estatuto da Criança e do Adolescente lei 8.069/90 (Lei n. $8069,2012)$. O aliciamento é considerado uma ação anterior ao abuso de crianças e adolescentes (Abrantes, 2016).

\section{Sessão 8: Feedbacks sobre as sessões}

Essa sessão se iniciou com a realização de uma retrospectiva de todos os ensinamentos teóricos que as mediadoras trouxeram ao grupo frente ao manejo parental e uso das tecnologias. Foi aberto um espaço para as mesmas relataram feedbacks negativos e positivos frente às sessões, bem como mudanças adquiridas no manejo parental. As participantes trouxeram o que conseguiram colocar em prática, alguns 
desafios e os resultados obtidos, referentes à categoria parentalidade, via relato de diário de campo:

Como um feedback negativo e uma dificuldade percebida pelos próprios participantes é a impossibilidade de todos os responsáveis que dividem os cuidados parentais com os adolescentes não estarem presentes juntos nas sessões. Acredita-se que o aprendizado em conjunto contribuiria para uma melhor compreensão $e$ aplicação do que foi trabalhado no mesmo propósito, para que ocorra de maneira mais eficaz. Elas atribuem ao horário das sessões um empecilho para que os outros cuidadores pudessem comparecer.

Como feedback positivo, a Cuidadora 1 mencionou que atualmente ela consegue conversar de forma franca com seu filho, expor os seus sentimentos e afeto, que convivem mais e que o adolescente convida a mãe para estudar próximo dele no tempo em que joga. A Cuidadora 2 pontuou o fato da neta estar se comunicando cada vez melhor com ela, e que as duas têm se relacionado mais. Mostrou-se grata pelos conhecimentos adquiridos, visto que para ela criar adolescentes imersos a tecnologia é algo novo. A Cuidadora 4, que também é avó, concordou com a Cuidadora 2 e disse que nunca imaginou que sendo avó aprenderia tanto em relação a cuidados parentais. A Cuidadora 5 afirmou que se deu conta de coisas do cotidiano que passam despercebidas e podem prejudicar os seus filhos.

Felizmente a partir do que as participantes trouxeram, $e$ principalmente do envolvimento que as mesmas obtiveram nos encontros, pode-se constatar que os objetivos propostos foram alcançados. Apresentou-se durante o encontro o
Baralho Disciplina Positiva para educar os filhos, com ferramentas práticas de manejo parental, como também todos os temas que foram trabalhados nas sessões, o que foi um fator propício para se determinar os aprendizados adquiridos, e trazer as participantes para o exemplo real, trazendo-se reflexão para o grupo.

"Durante a sessão foi percebido por parte das mediadoras que a união e o desejo do grupo fortaleceram as componentes, pois algumas vezes a questão de uma participante era semelhante a de outra, e com isso o aprendizado se fez de uma forma mútua e edificante".

Através das percepções dos cuidadores por meio dos feedbacks é possível uma maior eficácia das intervenções. A terapia cognitivacomportamental trabalha com a ferramenta de feedback, a mesma é fundamental para produzir engajamento do paciente ao atendimento seja realizado de forma individual ou coletiva. Também permite que os terapeutas ou mediadores de grupos juntamente com os participantes avaliam o processo e a evolução de cada sessão (Cacilhas, 2018).

\section{Encontro 2 (Pós-fase de intervenção): Encerramento e devolução das sessões}

Nesse dia, foi realizado encerramento das atividades grupais, bem como a devolução para as cuidadoras sobre as percepções das mediadoras acerca da evolução do grupo. Percebeu-se que, ao longo dos encontros, as cuidadoras se empenharam nas intervenções propostas e buscaram aplicar os aprendizados em suas famílias, principalmente na relação com os adolescentes. Foi abordado sobre o caráter reflexivo que os encontros proporcionaram ao abordar questões cotidianas de forma que fogem ao senso comum, como exemplo, a repercussão dos prejuízos do uso exagerado de tecnologia para além do distanciamento dos cuidadores, correlato com déficits cognitivos e sociais que vão além do contexto familiar. 
Debateu-se a importância de voltar à atenção para o uso que o cuidador faz da tecnologia, pois o adolescente também o utiliza como parâmetro e aprende com os cuidadores. As participantes também fizeram as suas devoluções, conforme descrição da categoria parentalidade do diário de campo:

Duas cuidadoras trouxeram cartas agradecendo a repercussão que o grupo teve em suas famílias. Todas as participantes presentes demonstraram interesse em continuar com as intervenções em grupo no próximo semestre.

\section{Conclusão}

Esta pesquisa apresentou sessões de um protocolo de intervenção realizadas com um grupo de cuidadoras de adolescentes, a partir de um projeto de extensão. Os relatos das participantes apontaram desconfortos e incertezas quanto a forma de exercer a parentalidade e de se relacionar com os desafios diante dos adolescentes. Demandas de manejo referente a questões comportamentais dos adolescentes foram trazidas ao grupo parental referente às dificuldades na comunicação social: isolamento ou falta de interesse em estar com outras pessoas, inaptidão para estabelecer amizades e relacionamentos afetivos e inabilidade em seguir uma rotina necessária para a idade cronológica. As participantes salientaram também a complexidade em dialogar e sobre o uso de telas em excess em suas famílias.

Embora a maneira de educar e se relacionar com os filhos vêm sendo muito pesquisada nas últimas décadas, o grupo do presente estudo demonstrou desconhecer informações a respeito do processo do que é comum ao desenvolvimento da adolescência, bem como as características do período da adolescência e técnicas de educação parental positiva, que possam orientar e ao mesmo tempo preservar os vínculos familiares. Durante o desenvolvimento das sessões evidenciou-se que fornecer os conhecimentos, relatados neste estudo, durante as sessões ao grupo, em uma linguagem simples, clara e acessível obteve caráter psicoeducacional.Durante as oito sessões de intervenção, bem como nos encontros pré e pós intervenção foram observadas, a partir do diário de campo das mediadoras do grupo, mudanças com impacto na vida cotidiana e funcional das famílias, a partir da orientação parental. A presença de comunicação mais efetiva, seguimento de rotina adequada para adolescentes, promoção de uma escuta ativa e fala mais clara e aberta com os adolescents foi relatada. Essas mudanças permitem uma redução da supressão parental em relação às necessidades básicas dos adolescents, assim como do tempo de telas limitado e extinção do comportamento de assistir a essas nos momentos de refeição. Ainda, maior entendimento sobre o desenvolvimento global da fase da adolescência foi percebida por parte das cuidadoras, conforme relato das mesmas.

Nesse estudo se encontrou como limitações o tamanho da amostra e o número de encontros. A partir desse panorama, aponta-se para estudos futuros a necessidade de uma maior participação incluindo além da figura materna, o pai e os demais responsáveis na relação com o adolescente, além de mais sessões de intervenções parentais, visando estimular o uso positivo de tal ferramenta, bem como orientar e promover a consciência dos riscos existentes do uso inadequado.

Nas intervenções realizadas com cuidadores há a possibilidade de uma aplicação direta do conhecimento de estilos e manejos parentais, de forma a munir os responsáveis pelos cuidados com os adolescentes com conhecimentos específicos e habilidades que permitam promover o desenvolvimento e a competência dos jovens. Um trabalho de instrução para cuidadores é de extrema importância, pois implica no melhor desenvolvimento dos adolescentes, que por sua vez serão os pais de amanhã, atingindo inclusive muitas outras gerações. 


\section{Referências}

Abrantes, A. C. S. (2016). O problema do aliciamento de menores através da internet para fins sexuais (Dissertação de Mestrado). Universidade Católica Portuguesa, Lisboa, Portugal. Recuperado de https://repositorio.ucp.pt/bitstream/10400.1 4/21940/1/Alexandra\%20Catarina\%20Silva \%20Abrantes.pdf

Ainsworth, M. D. S., Blehar, M. C., Waters E., \& Wall, S. N. (2015). Patterns of attachment: a psychological study of the strange situation. New York: Routledge.

Almeida Maia, F., \& Soares, A. B. (2019). Diferenças nas práticas parentais de pais e mães e a percepção dos filhos adolescentes. Estudos Interdisciplinares em Psicologia, 10(1), 59-82. doi: 10.5433/22366407.2019v10n1p59

Bardin, L. (2016). Análise de Conteúdo. São Paulo: Edições 70.

Barreto, M. J., \& Rabelo, A. A. (2015). A família e o papel desafiador dos pais de adolescentes na contemporaneidade. Pensando Famílias, 19(2), 34-42.

Recuperado de http://pepsic.bvsalud.org/scielo.php?script= sci_arttext\&pid=S1679494X2015000200004

Becker, D., \& Stein, G. (07 de fevereiro de 2020). Crianças \& telas. [Podcast áudio]. Recuperado de https://www.youtube.com/watch?v=LO8U daZIjw

Becker, A. P. S., Vieira, M. L., \& Crepaldi, M. A. (2019). Apego e parentalidade sob o enfoque transcultural: uma revisão da literatura. Psicogente, 22(42), 1-25. doi: 10.17081/psico.22.42.3507

Benetti, I. C., Vieira, M. L., \& Faracco, A. M. (2016). Suporte parental para crianças do ensino fundamental. Cadernos de pesquisa, 46(161), 784-801. doi: 10.1590/198053143424

Bettencourt, S. M. G. C. (2017). Parentalidade Positiva Estudo sobre a perceção da importância da participação em programas de educação parental
(Dissertação de Mestrado). Universidade da Madeira, Funchal, Portugal. Recuperado de https://digituma.uma.pt/bitstream/10400.13/ 1977/1/MestradoSoniaBettencourt.pdf

Bolsoni-Silva, A. T., \& Loureiro, S. R. (2011). Práticas educativas parentais e repertório comportamental infantil: comparando crianças diferenciadas pelo comportamento. Paidéia (Ribeirão Preto), 21(48), 61-71.

Recuperado de

https://www.scielo.br/scielo.php?pid=S010 3-

863X2011000100008\&script=sci_abstract \&tlng=es

Botton, A., Cúnico, S. D., Barcinski, M., \& Strey, M. N. (2015). Os papéis parentais nas famílias: analisando aspectos transgeracionais e de gênero. Pensando familias, 19(2), 43-56. Recuperado de http://pepsic.bvsalud.org/scielo.php?script= sci_arttext\&pid=S1679494X2015000200005

Bowlby, J. (1988a). A secure base: parentchild attachment and healthy human development. Basic Books. Recuperado de https://pdfs.semanticscholar.org/545b/9839 42722792c0e0c48b699aced98323d13e.pdf

Bowlby, J. (1989b). Uma base segura: Aplicações clínicas da teoria do apego. Porto Alegre: Artes Médicas.

Bowlby, J. (1997c). Formação e rompimento dos laços afetivos. São Paulo: Martins Fontes.

Bueno, G. R., \& Lucena, T. F. R. (2016). Geração cabeça-baixa: saúde e comportamento dos jovens no uso das tecnologias móveis. Simpósio Nacional ABCiber, 9, 573-578. Recuperado de http://abciber.org.br/publicacoes/livro3/text os/geracao_cabeca-

baixa_saude_e_comportamento_dos_joven s_no_uso_das_tecnologias_moveis_glauku S_regiani_bueno.pdf

Cacilhas, L. D. F. D. S. (2018). O uso de sistemas de feedback em psicoterapia: Um estudo sobre a perspectiva da díade terapêutica (Dissertação de Mestrado). Instituto Universitário Ciências 
Psicológicas, Sociais e da Vida, Lisboa,

Portugal. Recuperado de

http://repositorio.ispa.pt/bitstream/10400.12 16258/1/21698-OA.pdf

Fava, D. C., Rosa, M., \& Olivia, A.D. (2018).

Orientação para Pais. $O$ que é preciso saber para cuidar de um filho. Belo Horizonte: Artesã.

Freitas, M., \& Pereira, E. R. (2018). O diário de campo e suas possibilidades. Quaderns de Psicologia, 20(3), 235-244. doi:

10.5565/rev/qpsicologia.1461

Fonte L. (2017). A influência das novas formas de comunicação no desenvolvimento sócio-emocional das crianças. Revista de Psicopedagogia, 34(103), 75-86. Recuperado de: www.psicologia.com.com.pt/artigos/textos/ A0405.pdf

Garcia, N. M., Yunes, M. A. M., \& Almeida, A. M. T. (2016). Educação parental e pedagogia social: avaliação de uma proposta de intervenção. Educação, 39(1), 94-104. doi: $10.15448 / 1981$ 2582.2016.1.21396

Guisso, L., Bolze, S. D. A., \& Viera, M. L. (2019). Práticas parentais positivas e programas de treinamento parental: uma revisão sistemática da literatura. Contextos Clínicos, 12(1), 226-255. Recuperado de http://revistas.unisinos.br/index.php/context osclinicos/article/view/ctc.2019.121.10

Harlow, H. [Canal José Savóia] (21 de fevereiro de 2012). Harlow's Studies on Dependency in Monkeys [Arquivo de vídeo]. Recuperado de https://www.youtube.com/watch?v=qjiioO mWnqg

Lei $n$. 8069, de 13 de julho de 1990. Dispõe sobre o Estatuto da Criança e do Adolescente, e dá outras providências. Recuperado de http://www.crianca.mppr.mp.br/arquivos/Fi le/publi/camara/estatuto_crianca_adolescen te_9ed.pdf

Lima, A., \& Cardoso, A. M. P. (2018).

Orientação e treinamento de pais: uma vivência clínica. Doxa: Revista Brasileira de Psicologia e Educação, 20(1), 6-19. doi: 10.30715/rbpe.v20.n1.2018.10872
Maccoby, E. E., \& Martin, J. A. (1983).

Socialization in the context of the family: parent-child interaction. In P. H. Mussen, E. M. Hetherington (Eds.), Handbook of Child Psychology: Socialization, Personality and Social Development: Volume 4 (pp. 1-101). New York: Wiley.

Miranda, D. S. (2018). Marcadores funcionais da atividade elétrica do córtex cerebral para identificar atrasos no desenvolvimento de funções executivas no córtex pré frontal em adolescentes (Dissertação de Mestrado). Universidade Federal do Pará, Belém, Brasil. Recuperado de

http://repositorio.ufpa.br/jspui/bitstream/20 11/11100/1/Dissertacao_MarcadoresFuncio naisAtividade.pdf

Muszkat, M., Miranda, M. C., \& Muszkat, D. (2015). Neuropsicologia da adolescência. In F. H. Santos, V. M. Andrade, \& O. F. A. Bueno (Orgs.), Neuropsicologia Hoje (2a ed., Cap. 16, pp. 169-176). Porto Alegre: Artmed.

Naves, F. F. (2016). Interfaces entre a psicologia sócio-histórica e a educação popular com adolescentes. Gerais: Revista Interinstitucional de Psicologia, 9(1), 3249. Recuperado de http://pepsic.bvsalud.org/scielo.php?script= sci_abstract\&pid=S198382202016000100004

Nelsen, J. (2015). Disciplina positiva. Barueri: Manole

Nelsen, J., \& Lott, L. (2019). Disciplina positiva para adolescentes: uma abordagem gentil e firme na educação dos filhos ( $3^{\mathrm{a}}$ ed. Barueri). São Paulo: Manole.

Neufeld, C. B., Benedetti, T. B., \& Caminha, M. G. (2017). Orientação de pais em grupo. In C. B. Neufeld, \& B. P. Rangé (Orgs.), Terapia cognitivo comportamental em grupos: das evidências à prática (Cap. 18, pp. 503-520). Porto Alegre: Artmed.

Neufeld, C. B., Maltoni, J., Ivatiuk, A. L., Rangé, B. P. (2017). Aspectos técnicos e o processo em TCCG. In C. B. Neufeld, \& B. P. Rangé (Orgs.), Terapia cognitivo comportamental em grupos: das evidências 
à prática (Cap. 2, p. 58-93). Porto Alegre:

Artmed.

Neufeld, C. B., Godoi, K., Rebessi, I. P., Maehara, N. P., \& Mendes, A. I. F. (2018). Programa de orientação de pais em grupo: um estudo exploratório na abordagem cognitivo-comportamental. Psicologia em Pesquisa, 12(3), 1-11. doi: $10.24879 / 2018001200300500$

Neves, M. O. (2015). A importância da investigação qualitativa no processo de formação continuada de professores: subsídios ao exercício da docência. Revista Fundamentos, 2(1). Recuperado de https://revistas.ufpi.br/index.php/fundament os/article/view/3723

Park, J. H., Han, D. H., Kim, B. N., Cheong, J. H., \& Lee, Y. S. (2016). Correlations among social anxiety, self-esteem, impulsivity, and game genre in patients with problematic online game playing. Psychiatry Investigation, 13(3), 297-304. doi: $10.4306 /$ pi.2016.13.3.297

Pazzetto, T. \& Toni, C. G. S. (2018). Grupo de orientação a pais em clínica-escola de psicologia. Revista PsicoFAE, 7(2), 69-86. Recuperado de https://revistapsicofae.fae.edu/psico/article/ view/183

Pereira M. N. (2015). A Superexposição de crianças e adolescentes nas redes sociais: necessária cautela no uso das novas tecnologias. Anais do Congresso Internacional de Direito e Contemporaneidade: mídias e direitos da sociedade em rede. Santa Maria, Rio Grande do Sul, Brasil. Recuperado de http://www.ufsm.br/congressodireito/anais

Ramires, V. R. R., \& Schneider, M. S. (2010). Revisitando alguns conceitos da teoria do apego: comportamento versus representação? Psicologia: teoria e pesquisa, 26(1), 25-33. Recuperado de http://www.scielo.br/pdf/ptp/v26n1/a04v26 n1.pdf

Rodrigues, M. F. da S. (2019). Efeitos de um programa preventivo de orientação parental com base em práticas positivas: coletânea de casos (Dissertação de mestrado). Universidade Presbiteriana Mackenzie, São
Paulo, Brasil. Recuperado de http://tede.mackenzie.br/jspui/handle/tede/3 908

Rosenberg, M. B. (2019a). A linguagem da paz em um mundo de conflitos: sua próxima fala mudará seu mundo. São Paulo: Palas Athena.

Rosenberg, M. B. (2019b). Vivendo a comunicação não violenta. Rio de Janeiro: Sextante.

Sales, E. T. (2016). A influência do contexto familiar na saúde mental das crianças e adolescentes. Revista da Faculdade Itecne, 2(1), 1-8. Recuperado de http://itecne.com.br/social/edicoes/2016/arti gos/Artigo\% 20(4).pdf

Senna, S. R. C. M., \& Dessen, M. A. (2015). Reflexões sobre a saúde do adolescente brasileiro. Psicologia, Saúde \& Doenças, 16(2), 217-229. doi: $10.15309 / 15 \mathrm{psd} 160208$

Siegel, D. J. (2016). Cérebro adolescente: a coragem e a criatividade da mente dos 12 aos 24 anos. São Paulo: nVersos.

Silva, R. V. B. (2015). Os conflitos na fronteira de contato entre os pais e seus filhos adolescentes Conflicts on the Border of Contact Between Parents and their Adolescent's Son. IGT na Rede, 12(22). Recuperado de https://www.igt.psc.br/ojs/viewarticle.php?i $\mathrm{d}=479$ \&layout $=\mathrm{html}$

Silva T. de O., \& Silva, L. T. G. (2017). Os impactos sociais, cognitivos e afetivos sobre a geração de adolescentes conectados às tecnologias digitais. Revista Psicopedagogia, 34(103), 87-97.

Recuperado de http://pepsic.bvsalud.org/scielo.php?script= sci_arttext\&pid=S0103$84862017000100009 \& \operatorname{lng}=\mathrm{pt} \& \mathrm{t} \operatorname{lng}=\mathrm{pt}$

Sousa, M. L. D., \& Cruz, O. (2016). A

Relação entre as Representações acerca das Figuras Parentais e as Competências Sociais em Crianças Maltratadas e não Maltratadas. Psicologia: Teoria e Pesquisa, 32(2). doi: 10.1590/0102-3772e32224

Spizzirri, R., Wagner, A., Mosmann, C., \& Armani, A. (2012). Adolescência conectada: Mapeando o uso da internet em 
jovens internautas. Psicologia Argumento, 30(69), 327-335. Recuperado de

https://periodicos.pucpr.br/index.php/psicol ogiaargumento/article/view/23288/22361

TIC kids online Brasil. (2018). Pesquisa sobre o uso da internet por crianças e adolescentes no Brasil. Núcleo de Informação e Coordenação do Ponto. Comitê Gestor da Internet no Brasil. São Paulo, Brasil. Recuperado de https://cetic.br/media/docs/publicacoes/216 370220191105/tic kids_online 2018 livro eletronico.pdf

Wainer, R., \& Wainer, G. (2011). Treinamento de pais para o transtorno de conduta e o transtorno desafiador de oposição. In M. G. Caminha, \& R. Caminha (Orgs.), Intervenções e Treinamento de pais na clínica infantil (pp. 207-240). Porto Alegre: Sinopsys.

Wainer, R., \& Wainer, G. (2016). O trabalho com os modos esquemáticos. In K. Paim, R. Erdos, \& R. Andriola (Orgs.), Terapia cognitiva focada em esquemas: integração em Psicoterapia (s.p). Porto Alegre:

Artmed.

World Health Organization [WHO]. (2017). Global accelerated action for the health of adolescents (AA-HA!): guidance to support country implementation. World Health Organization. Recuperado de https://www.who.int/publications/i/item/glo bal-accelerated-action-for-the-health-ofadolescents-(-aa-ha!)-guidance-to-supportcountry-implementation 


\section{Dados sobre as autoras:}

- Ana Claudia Pinto da Silva: Graduanda do Curso de Psicologia da Universidade Franciscana (UFN). Bolsista PROBEX-UFN.

- Monique Corrêa de Melo Santiago: Pedagoga, Pós Graduanda em Psicopedagogia Clínica e Institucional (Uniasselvi) e Educadora Parental pela Positive Discipline Association (EUA).

- Jessica Aguiar: Graduanda do Curso de Psicologia da Universidade Franciscana (UFN).

- Luiza Müller Rubert: Graduanda do Curso de Psicologia da Universidade Franciscana (UFN).

- Paula Argemi Cassel: Psicóloga, Mestre em Psicologia Clínica pela Pontifícia Universidade Católica do Rio Grande do Sul (PUCRS).

- Marcli Firpo Bittencourt: Psicóloga, Mestranda em Saúde Materno Infantil da Universidade Franciscana (UFN).

- Josiane Lieberknecht Wathier Abaid: Psicóloga, Doutora em Psicologia pela Universidade Federal do Rio Grande do Sul (UFRGS), Docente do Mestrado Profissional em Saúde Materno Infantil da Universidade Franciscana (UFN).

\section{Agradecimentos:}

Agradecemos às cuidadoras que aceitaram participar do projeto de extensão, ao Laboratório de Práticas da Universidade e à equipe de apoio do Projeto maior e à Universidade Franciscana, pela bolsa de extensão.

Declaração de Direito Autoral

A submissão de originais para este periódico implica na transferência, pelos autores, dos direitos de publicação impressa e digital. Os direitos autorais para os artigos publicados são do autor, com direitos do periódico sobre a primeira publicação. Os autores somente poderão utilizar os mesmos resultados em outras publicações indicando claramente este periódico como o meio da publicação original. Em virtude de sermos um periódico de acesso aberto, permite-se o uso gratuito dos artigos em aplicações educacionais e científicas desde que citada a fonte conforme a licença CC-BY da Creative Commons. 